\title{
Cidadãos globais: competência internacional e conflito de leis na jurisprudência brasileira de direito de família e sucessões*
}

\author{
Global citizens: conflicts of jurisdiction \\ and law in the brazilian family and \\ inheritance case law
}

Gustavo Ferreira Ribeiro ${ }^{1}$

Recebido em: 26/08/2015.

Aprovado em: 02/10/2015.

Professor do Programa de Mestrado/Doutorado do UniCEUB-Brasília das disciplinas Conflito de Leis no Espaço: uma abordagem juseconômica, Direito Internacional Econômico e Análise Econômica do Direito. Professor na Graduação de Direito Internacional Privado. Obteve seu doutorado pleno em Direito Internacional pela Maurer School of Law, Indiana University Bloomington (EUA), como bolsista do programa CAPES/FULBRIGHT (revalidado UFSC, 2010). Mestre em Direito (UFSC, 2004). Bacharel em Direito (UFMG, 2002) e Ciência da Computação (UFMG, 1996). Consultor-Senior UNODC (2013), em Cooperação Jurídica Internacional junto ao Ministério da Justiça. Consultor-Senior UNDP (2012), em Promoção Comercial junto ao Ministério das Relações Exteriores. Foi Diretor (2010-2011) do Departamento de Normas e Competitividade em Comércio Exterior (DENOC) e Coordenador-Geral de Organismos Internacionais (2010) do Ministério do Desenvolvimento, Indústria e Comércio Exterior (MDIC). Advogado. Tem como interesses atuais: direito internacional, direito e economia e o desenvolvimento de simuladores e jogos pedagógicos nessas áreas.

\section{Resumo}

O termo cidadão global pode designar pessoas que se julgam pertencer a uma comunidade global, sem um vínculo específico a uma nacionalidade ou soberania. Ao mesmo tempo, o termo é utilizado para se referir simplesmente à mobilidade das pessoas, em um contexto de globalização. Levando em conta este último aspecto, relevantes questões práticas surgem no que toca o Direito Privado, comumente tratadas, para alguns, na "misteriosa" disciplina Direito Internacional Privado. O objetivo deste artigo consiste em, por meio de estudo de casos multijurisdicionados, ilustrar e distinguir os tipos de questões recorrentes envolvendo conflitos de competência e de leis, em Direito de Família e Sucessões. A amostra inicial do estudo contemplava 141 (cento e quarenta e uma) decisões coletadas dos Tribunais de Justiça do Brasil (2004-2013) reduzidas, por sucessivos recortes, a um conjunto de 6 (seis) decisões nas quais se discutiu, concomitantemente, conflitos de competência internacional e de direito material aplicável nas áreas indicadas.

Palavras-chave: Direito Privado. Direito Internacional Privado. Competência Internacional. Conflito de Leis. Família. Sucessão.

\section{Abstract}

The term global citizen may refer to a person asserting himself as pertaining to a global community, without a specific relationship to a nationality or sovereignty. At the same time, it is used as a reference to people's mobility, in the context of globalization. Taking into account the latter meaning, practical issues appear in respect to private law, commonly treated, in someone's view, by the "mysterious" discipline called Private International Law. Through multistate case analysis, this article aims at illustrating and distinguishing the types of recurrent issues involving conflicts of jurisdiction and law in the realm of Brazilian Family and Inheritance Law. The initial sample of the study gathers 141 decisions extracted from the Brazilian State Courts of Appeal from 2004-2013. After the application of several filters, the article analyzes a final set of six decisions containing debates of conflicts of international jurisdiction and law in the concerned matter.

Keywords: Private Law. Private International Law. Conflicts of Jurisdiction. Conflicts of Law. Family. Inheritance Law. 


\section{Introdução}

O objetivo deste artigo consiste em, por meio de pesquisa na jurisprudência brasileira, ilustrar e diferenciar os tipos de questões recorrentes que tocam competência internacional e aplicação do direito material estrangeiro, em Direito de Família e Sucessões. A relevância do tema é notória, em face da crescente mobilidade de cidadãos globais.

O termo cidadão global é utilizado de forma imprecisa na linguagem. De forma geral, designa aqueles que se julgam pertencer a uma comunidade mais ampla, sem referência a uma nacionalidade ou Estado específico. ${ }^{2}$ Espécies dessa cidadania se concretizam, em distintos graus, no âmbito de integração regional, sendo exemplos os projetos e as ambições europeias, latino-americanas e mercosulinas. Encontra-se ainda a utilização coloquial do termo como alusão à mobilidade de pessoas, em um contexto de globalização. ${ }^{3}$

Levando-se em conta o último sentido, ao se movimentarem entre jurisdições, questões de Direito Privado relacionadas à vida dessas pessoas merecem maior aprofundamento. Com efeito, ao cruzarem fronteiras, de forma temporária ou permanente, em situação regular ou não, engajam estes cidadãos em relações jurídicas por meio de contratos, trabalho, relações familiares (casamentos, uniões e divórcios) e sucessórias.

2 Deve-se esclarecer que, ao lado da imprecisão do termo "cidadão global", convivem conceitos mais precisos, como o de nacionalidade e cidadania presentes na doutrina de Direito Internacional Público, Direito Constitucional, Direito Internacional Privado, entre outras. Em relação a esse último ramo, Dolinger, ao atentar para certa confusão terminológica proveniente do direito anglo-saxão, relembra a distinção doutrinária, adotada no Brasil, na qual "nacionalidade é o vínculo jurídico que une, liga, vincula, o indivíduo ao Estado e a cidadania representa um conteúdo adicional, de caráter político, que faculta à pessoa certos direitos políticos, como o de votar e ser eleito." DOLINGER, Jacob. Direito internacional privado. 6. ed. Rio de Janeiro: Renovar, 2001. p. 153. Ressalve-se, igualmente, que, ao lado do pretenso cidadão global, encontra-se o "cidadão" global. Sua inserção no mundo tem pouco a ver com o sentimento de pertencimento a uma comunidade global ou regional. Pelo contrário, muitas vezes, decorre da urgência em sobreviver, seja na condição de imigrante irregular ou refugiado. São situações mais do que atuais e verificáveis na história da humanidade, relacionando-se a disputas econômicas, preconceito, guerras e perseguições que, em si, justificariam um trabalho à parte.

3 Nesse sentido, os avanços relativos aos meios de transporte e tecnológicos são vetores dessa mobilidade. É de se notar a referência à "aldeia global”, cunhada por McLuhan, tendo como substrato a integração das pessoas pelos meios tecnológicos MCLUHAN, M. A. Galáxia de Gutenberg: a formação do homem tipográfico. São Paulo: Nacional, 1977.
Emerge daí, naturalmente, problemas de competência internacional ${ }^{4}$ e conflitos de leis no espaço. Estando a relação jurídica conectada a mais de uma jurisdição, qual a justiça internacionalmente competente para conhecer da causa? Assumindo-se a competência internacional da justiça brasileira, devem essas relações ser regidas pelo direito substantivo brasileiro, estrangeiro ou uma combinação deles?

No caso brasileiro, as questões relativas à competência internacional são reguladas, principalmente, no atual Código de Processo Civil (CPC), em seus artigos 88 a $89 .{ }^{5}$ Já os artigos 7 e seguintes do Decreto-Lei 4.657 (1942), anteriormente conhecido como Lei de Introdução do Código Civil (LICC), renomeado, em 2012, Lei de Introdução às Normas de Direito Brasileiro (LINDB), cuidam da resolução dos conflitos de leis (conflito espacial), trazendo regras sobre a lei aplicável para as diversas relações jurídicas (família, sucessões, contratos). Contra intuitivamente, a LINDB, assim como a legislação comparada, prevê a aplicação do direito material estrangeiro, atendidas certas condições.

São questões pouco estudadas e superficialmente vistas, nas faculdades de Direito brasileiras, normalmente sob a denominação da disciplina Direito Internacional Privado. ${ }^{6}$ Não por falta de tradição no assunto. Dolinger

$4 \quad$ Neste artigo, utilizam-se primordialmente as expressões competência internacional, competência internacional da justiça brasileira e justiça internacionalmente competente. A possível crítica é que as expressões não trazem em si uma modalidade de competência (como limite à jurisdição ou parcela da jurisdição entregue a determinado órgão), mas tratam de questão anterior, na qual se determina, em casos conectados a mais de uma jurisdição, a jurisdição competente (doméstica, internacional) e a sua qualidade (concorrente ou exclusiva). Não obstante, a utilização está em consonância com à denominação do Capítulo II - contendo os arts. 88-90 - do CPC, embora não haja uniformidade na práxis dos tribunais.

5 CPC, "Art. 88. É competente a autoridade judiciária brasileira quando: I - o réu, qualquer que seja a sua nacionalidade, estiver domiciliado no Brasil; II - no Brasil tiver de ser cumprida a obrigação; III - a ação se originar de fato ocorrido ou de ato praticado no Brasil. [...] Art. 89. Compete à autoridade judiciária brasileira, com exclusão de qualquer outra: I - conhecer de ações relativas a imóveis situados no Brasil; II - proceder a inventário e partilha de bens, situados no Brasil, ainda que o autor da herança seja estrangeiro e tenha residido fora do território nacional." Para o Novo Código de Processo Civil (Lei 13.105, de 16 de março de 2015), vejam-se artigos 21-24.

6 Nos Estados Unidos, corresponde à disciplina "Conflito de Leis”, embora nessa nação muito desses conflitos sejam de ordem interna à Federação Norte-Americana, em função da autonomia das unidades para legislar em matéria civil. 
enumera a vasta profusão de doutrinadores brasileiros, desde a obra seminal de Pimenta Bueno (1863), passando por autores como Eduardo Spínola, Oscar Tenório, Rodrigo Otávio e Haroldo Valadão. ${ }^{7}$ Talvez pela sua complexidade, notada também em outras jurisdições.

Ironicamente, referindo-se a uma constatação da década de 1950 de um tradicional autor norte-americano, Juenger relembra o campo de atuação da disciplina como um apavorante pântano cheio de lama e habitado por cultos, mas excêntricos, professores que teorizam sobre matérias misteriosas com um jargão estranho e incompreensível. ${ }^{8}$

Reconhecendo sua dificuldade, sobre a qual renomados juristas já devotaram esforços (Bartolus, Story e Savigny), Juenger agrupa os problemas da disciplina em três grandes temas:

1. Jurisdição. i.e., se uma Corte de um Estado ou Nação em particular pode conhecer de um caso;

2. Direito Aplicável, i.e., qual o direito a Corte irá aplicar se ela conhecer do caso;

3. Reconhecimento e execução de decisões, i.e., qual a extensão esperada por outros Estados e Nações em "honrar" as decisões judiciais que efetivamente decidiu disputas. ${ }^{9}$

Este artigo explorará, especificamente, as duas primeiras questões, em casos de Direito de Família e Sucessões. Partindo-se de amostra inicial de 141 decisões coletadas dos Tribunais de Justiça do Brasil (2004-2013), foi delimitado um conjunto de 6 (seis) decisões em que discutiram-se, concomitantemente, os pontos citados.

Quanto a sua organização, o artigo se desenvolve em três partes. Inicialmente (Seção 2.1 - Metodologia), expõe-se a metodologia utilizada na seleção dos casos. Em seguida, passa-se à descrição dos casos e às considerações analíticas pertinentes (Seção 2.2), dividindo-se a seção em duas temáticas: Casamento, União Estável e Divórcio (2.2.1); e Sucessão (2.2.2).

Mais do que se posicionar sobre pontos específi-

DOLINGER, Jacob; TIBURCIO, Carmen. O DIP no Brasil no século XXI. Revista Mexicana de Derecho Internacional Privado, Cidade do México, número especial, p. 79-95, 2000.

$8 \quad$ JUENGER, Friedrich K. General Course on Private International Law. Hague, [1983]. p. 131.

9 JUENGER, Friedrich K. General Course on Private International Law. Hague, [1983]. p. 133. Observa-se que se trata de sistematização adotada por grande parte da doutrina de DIPr, não se determinando se sua autoria é originariamente de Juenger. cos da interpretação carreada pelas cortes nacionais ou avançar uma análise estatística, o artigo ilustra e diferencia os problemas que surgem de relações jurídicas multiconectadas.

\section{Desenvolvimento}

\subsection{Da metodologia de pesquisa da jurisprudência}

Em oportunidade anterior de publicação, já se detalhou a metodologia de extração da amostra, também utilizada nesta pesquisa. ${ }^{10}$ Nela se descreveram os critérios de pesquisa, tamanho original da amostra, classificação das categorias de casos, cortes utilizados, bem como as justificativas pertinentes de sua redução.

Neste artigo, salienta-se apenas que se está diante do mesmo corte temporal (1 de janeiro de 2004 a 31 de dezembro de 2013) sobre decisões colhidas dos vinte e sete Tribunais de Justiças das Unidades da Federação, contendo categorias de problemas que tratam simultaneamente dos dois primeiros problemas enumerados por Juenger (conflito de competência e direito material aplicável). ${ }^{11}$ Obteve-se, assim, um conjunto de 6 (seis) casos analisados qualitativamente a partir da próxima seção.

\subsection{Da análise qualitativa}

A análise está distribuída em dois temas: (i) Casamento, União Estável e Divórcio; e (ii) Sucessão. Na medida do possível, relatou-se, para cada caso, os fatos constantes nas respectivas decisões. Na sequência, trazem-se os resumos dos argumentos das partes e a discussão de competência e conflito de leis.

Como o foco do trabalho consiste em, primordialmente, ilustrar e diferenciar as questões de direito suscitadas, os nomes dos litigantes e questões procedimentais são apresentados apenas para o auxílio narrativo.

\subsubsection{Casamento, União Estável e Divórcio}

HG v. JB (2009)

O caso envolve, entre outros pontos, discussões de competência internacional e direito aplicável à união

10 RIBEIRO, Gustavo Ferreira; LUPI, André Lipp Pinto Basto. A aplicação do direito material estrangeiro em contratos pelos tribunais de justiça brasileiros: uma análise sobre dez anos de jurisprudência (2004-2013). Revista Nomos, Fortaleza, v. 34, n. 1, p. 81-107, jan/jun 2014. p. 83-85.

11 Adicionalmente, eliminaram-se os casos sob segredo de justiça, bem como aqueles no qual havia discussão exclusiva sobre o conflito de competência internacional, sem aprofundamento sobre o conflito material de leis. 
estável entre brasileira (HG) e estrangeiro (JB, alemão). Reporta o Acórdão que HG contou ter conhecido JB em 1996, convivido maritalmente e engravidado dele, perdurando tal união até março de 2004. ${ }^{12}$ Sustentou HG que, entre dezembro de 1999 a meados de 2003, residiram na Alemanha, dando continuidade à união no Brasil.

Com o fim do relacionamento, houve a propositura de uma ação no Brasil de reconhecimento e dissolução de união estável proposta por HG (autora) em face de JB (requerido), com a consequente partilha dos bens e valores adquiridos na constância da união. ${ }^{13}$ Além de bens comuns no Brasil, a autora aduziu que o requerido possuía, em 2003, valores em sua conta corrente na Alemanha, sobre os quais possuiria direitos, objeto de uma apelação cível.

Surgem as seguintes questões: é a justiça brasileira competente para conhecer do reconhecimento e dissolução da união? Também o é para determinar a divisão dos bens no exterior? Se sim, segundo as normas substantivas brasileiras ou alemãs?

\section{Análise da Decisão}

Quanto à competência internacional da justiça brasileira para o reconhecimento e dissolução da união estável, não há maiores discussões no Acordão, assumindo-se que não tenha sido um ponto objeto de apelação, nesse caso. ${ }^{14}$

Com relação à partilha dos bens, entretanto, tecem-se diversas considerações. Em primeiro grau, julgou-se parcialmente procedente os pedidos constantes da inicial para reconhecer a união estável, mas partilhar apenas os bens onerosamente adquiridos pelo casal no Brasil. Inconformada, a autora apelou, apontando que a LINDB teria abandonado o princípio da nacionalidade e consagrado o princípio do domicílio, indicando dispositivos da LINDB que sugeririam uma "unidade patrimonial" dos

12 DISTRITO FEDERAL. Tribunal de Justiça do Distrito Federal e Territórios. Apelação. Ap. 20040110522404. 1 ${ }^{\text {a }}$ Turma Cível. Apelante: HG. Apelado: JB. Relator: Desembargador Lécio Resende. São Paulo, 06 de agosto de 2009.

13 DISTRITO FEDERAL. Tribunal de Justiça do Distrito Federal e Territórios. Apelação. Ap. 20040110522404. 1 ${ }^{\text {a }}$ Turma Cível. Apelante: HG. Apelado: JB. Relator: Desembargador Lécio Resende. São Paulo, 06 de agosto de 2009. p. 2-3.

14 Somente se lembra o leitor das hipóteses do art. 88 do CPC e a prevista no inciso I do art. 100 do mesmo diploma, embora entenda esse autor que a primeira (competência internacional) preceda a discussão da competência interna, como já salientado. bens, independentemente de sua localização. ${ }^{15}$ Configurar-se-ia, assim, um conflito de leis no qual a autora pleiteava a regra brasileira de comunhão parcial dos bens não só sobre aqueles localizados no Brasil, mas também aos localizados na Alemanha (valores depositados em banco naquele país).

O Relator do caso, com menção ao parecer da Procuradoria de Justiça, indicou que o reconhecimento e dissolução da união estável pelo juízo a quo, com a aplicação do regime da comunhão parcial, "não autoriza concluir possa o magistrado singular extrapolar os limites de jurisdição brasileira" ${ }^{16}$ Amparou-se o Relator no caput do artigo 8 da $\operatorname{LINDB}^{17}$ que reza ser aplicável a lei brasileira apenas aos casos em que o bem, móvel ou imóvel, aqui se encontre ou que para o Brasil tenha sido transferido.

Nesse ponto, retoma-se a questão da competência internacional para a divisão dos bens. Segundo o Relator, os artigos 88 - 90 do CPC refletem limitação territorial que "visa manter a boa convivência entre Estados soberanos". ${ }^{18}$ O Relator se apoiou na jurisprudência do $\mathrm{STJ}^{19}$ e TJ-MG ${ }^{20}$ sublinhando que "a partilha adquiridos pelo casal na constância da união estável se resume ao patrimônio situado no território nacional, não sendo competente o Estado brasileiro para regular a partilha dos bens situados fora do país." Refutou, assim, a aplicação da regra brasileira, antes de tudo por uma questão

DISTRITO FEDERAL. Tribunal de Justiça do Distrito Federal e Territórios. Apelação. Ap. 20040110522404. 1a Turma Cível. Apelante: HG. Apelado: JB. Relator: Desembargador Lécio Resende. São Paulo, 06 de agosto de 2009. p. 2-3. Dispositivo concernente da LINDB, art. 10, caput: "A sucessão por morte ou por ausência obedece à lei do país em que domiciliado o defunto ou o desaparecido, qualquer que seja a natureza e a situação dos bens".

16 DISTRITO FEDERAL. Tribunal de Justiça do Distrito Federal e Territórios. Apelação. Ap. 20040110522404. 1a Turma Cível. Apelante: HG. Apelado: JB. Relator: Desembargador Lécio Resende. São Paulo, 06 de agosto de 2009. p. 4. 17 LINDB, art. 8, caput: "Para qualificar os bens e regular as relações a eles concernentes, aplicar-se-á a lei do país em que estiverem situados".

18 DISTRITO FEDERAL. Tribunal de Justiça do Distrito Federal e Territórios. Apelação. Ap. 20040110522404, 1a Turma Cível. Apelante: HG. Apelado: JB. Relator: Desembargador Lécio Resende. São Paulo, 06 de agosto de 2009. p. 4.

19 Jurisprudência de 2005, citada como: BRASIL. Superior Tribunal de Justiça. Recurso Especial. REsp 510.084/SP. $3^{\text {a }}$ Turma. Relatora: Ministra Nancy Andrighi. Brasília, 04 de agosto de 2005. p. 398.

20 Jurisprudência de 2007, citada como: MINAS GERAIS. Apelação Cível. Ap. n. 1.0024.04.310110-4/005. 5a Turma. Relatora: Desembargadora Maria Elza. Belo Horizonte, 06 de setembro de 2007. 
de conflito de competência, não tendo sido necessário resolver o conflito de leis no espaço, como requerido pela apelante. ${ }^{21}$

Outro ponto importante do Acórdão consiste na digressão sobre o tipo de incentivo que a regra de limitação territorial de competência proporciona. Poderia induzir à fraude já que, se um dos companheiros pretendesse se furtar à aplicação da lei brasileira, bastaria migrar os recursos financeiros do casal para depósito no exterior, afastando-os da divisão em partes iguais. Porém, o Relator salientou ser uma análise caso a caso; naquele em tela, os valores depositados na conta do requerido foram lá inicialmente depositados, não havendo indícios de fraude. ${ }^{22}$

O próximo caso traz discussão similar no âmbito de um divórcio multiconectado.

\section{$J L M R$ v. MBR (2010)}

O caso JLMR v. MBR envolvia cônjuges com patrimônio em mais de uma jurisdição. Por ocasião de dissolução conjugal entre JLMR e MBR, pleiteou a autora (MBR), inter alia, em sede de ação cautelar de arrolamento de bens, com pedido de liminar, a inclusão de bens localizados no Paraguai, na partilha. ${ }^{23}$

Surgem questões similares ao caso anterior, em sede de divórcio: é a justiça brasileira competente para determinar a partilha, advinda do divórcio, de bens no exterior? Qual o direito material aplicável?

\section{Análise da Decisão}

O juiz singular entendeu que a jurisdição nacional seria incompetente para realizar a partilha de bens situados em território estrangeiro (Paraguai), indeferindo o arrolamento dos bens de propriedade do requerido, situado no Paraguai. Em agravo de instrumento, enten-

21 DISTRITO FEDERAL. TJDFT. Apelação. Ap. 20040110522404. 1a Turma Cível do Tribunal de Justiça do Distrito Federal e Territórios. Apelante: HG. Apelado: JB. Relator: Desembargador Lécio Resende. São Paulo, 06 de agosto de 2009. p. 5.

22 DISTRITO FEDERAL. TJDFT. Apelação. Ap. 20040110522404, 1a Turma Cível do Tribunal de Justiça do Distrito Federal e Territórios. Apelante: HG. Apelado: JB. Relator: Desembargador Lécio Resende. São Paulo, 06 de agosto de 2009. p. 5.

23 Agravo Regimental em Agravo de Instrumento. MATO GROSSO DO SUL. Tribunal de Justiça do Mato Grosso do Sul. Agravo Regimental em Agravo de Instrumento. AgReg em Ag 2010.014850-7/0001-00. 5a Turma Cível. Agravante: JLMR. Agravado: MBR. Relator: Desembargador Vladimir Abreu da Silva. Campo Grande, 12 de agosto de 2010. deu-se diferentemente, decidindo o Relator, ao se referir à lição de Maria Helena Diniz, ${ }^{24}$ que o caso é uma

exceção à regra insculpida nos artigos $8^{\circ}$ e 12 , ambos da Lei de Introdução ao Código Civil, combinada com o artigo 89 do Código de Processo Civil, como sendo esta a regra da territorialidade ou lex rei sitae, pois tratando-se de cautelar de arrolamento de bens de patrimônio conjugal, a fim de preparar a partilha de bens em ação de dissolução de sociedade conjugal, os bens imóveis localizados no Paraguai, são uti universitas. ${ }^{25}$

A doutrina de Oscar Tenório, outrossim, foi trazida à baila, para se afirmar que [n]o sistema brasileiro, os bens que formam uma universalidade ficam sujeitos à lei daquele em cujo benefício é constituído o instituto o que nem sempre tem fácil aplicação no plano internacional. ${ }^{26}$

Em sede de agravo regimental, revelaram-se duas posições antagônicas sobre a matéria.

A posição vencedora do Relator, por maioria, posteriormente acompanhada pelo segundo Vogal, corroborou a doutrina da universalidade dos bens em partilha, devendo-se aplicar, no conflito de leis, apenas uma lei, no caso a brasileira:

o entendimento externado [no agravo de instrumento] não extrapola a soberania do $\mathrm{Pa}$ raguai, e é fácil de verificar o porquê, como também a necessidade de se aplicar esse entendimento, pois como tido anteriormente as ações universais, como espólio, patrimônio, conjugal, versam invariavelmente sobre o regime de bens do de cujos ou dos nubentes, os quais uma vez sendo brasileiros, e casados aqui no Brasil, sob o regime de bens da lei brasileira, não poderá ficar no crivo da legislação estrangeira, a partilha desses bens. ${ }^{27}$

A posição vencida, do primeiro Vogal, por outro

24 Obra de 2002, citada da seguinte forma: DINIZ, Maria Helena. Lei de introdução ao Código Civil Brasileiro interpretada. São Paulo: Saraiva, 2000. p. 269-270.

25 MATO GROSSO DO SUL. Tribunal de Justiça do Mato Grosso do Sul. Agravo Regimental em Agravo de Instrumento. AgReg em Ag 2010.014850-7/0001-00. 5a Turma Cível. Agravante: JLMR. Agravado: MBR. Relator: Desembargador Vladimir Abreu da Silva. Campo Grande, 12 de agosto de 2010. p. 4. Grifos retirados.

26 Citação sem referência ao ano de publicação, da seguinte forma: TENÓRIO, Oscar. Direito internacional privado. 11. ed. Rio de Janeiro: Biblioteca Jurídica Freitas Bastos, [1976]. v. 2. p. 166.

27 MATO GROSSO DO SUL. Tribunal de Justiça do Mato Grosso do Sul. Agravo Regimental em Agravo de Instrumento. AgReg em Ag 2010.014850-7/0001-00. 5a Turma Cível. Agravante: JLMR. Agravado: MBR. Relator: Desembargador Vladimir Abreu da Silva. Campo Grande, 12 de agosto de 2010. p. 6. 
lado, ateve-se à questão da competência internacional, disposta no artigo $89^{\circ}$, II, do CPC e a interpretação que se faz, a contrario sensu, do referido artigo. Por ela, a autoridade judiciária brasileira não tem jurisdição (competência internacional) para proceder ao arrolamento cautelar de bens e à respectiva partilha, sob pena de invasão da soberania de outro Estado. Recorreu o primeiro Vogal a julgados do $\mathrm{STJ}^{28}$ do $\mathrm{STF}^{29}$ à doutrina de Celso Agrícola Barbi, ${ }^{30}$ às lições de Marcus Vinicius Rios Gonçalves ${ }^{31}$ para reconhecer ser

\begin{abstract}
forçoso convir, conforme se extrai da lição da doutrina mais autorizada, que o arrolamento de bens no Estado estrangeiro dificulta sobremaneira o cumprimento das decisões judiciais pátrias, sobretudo pelos entraves burocráticos sempre existentes quando se trata de assunto de direito internacional. Por isso, não sem propósito, é que a jurisprudência do STJ já firmou posicionamento sobre o caso em tela, orientando no sentido que descabe à jurisdição brasileira o arrolamento e partilha de bens situados no exterior. $^{32}$
\end{abstract}

Não obstante, o segundo Vogal acompanhou o Relator por entender que o artigo 89, II, do CPC "não tem aplicação ao caso em julgamento, pois se refere à disciplina afeta à sucessão causa mortis de bens, e não separação ou divórcio de cônjuges". Mais ainda, em conformidade com as regras nacionais, entendeu que a decisão a quem restará o imóvel localizado no Paraguai seria feita no Brasil. Já no Paraguai, de acordo com as suas regras (em respeito ao artigo $8^{\circ}$, da LINDB), proceder-se-ia ao trâmite procedimental; qual seja, a transferência de propriedade,

28 Jurisprudências citadas: BRASIL. Superior Tribunal de Justiça. Recurso Especial. REsp 510084/SP. 3a Turma. Relatora: Ministra Nancy Andrighi. Brasília, 04 de agosto de 2005. p. 398; BRASIL. Superior Tribunal de Justiça. Recurso Especial. REsp 275985/SP. 4a Turma. Relator: Ministro Sálvio de Figueiredo Teixeira. Brasília, 17 de junho de 2003. p. 366.

29 Jurisprudência de 1984 citada como: BRASIL. Supremo Tribunal Federal. Recurso Extraordinário. RE 99.230-RS. $1^{\text {a }}$ Turma. Recorrentes: Jovita Albernoz Serralta e outros. Recorrida: Nely Braz. Relator: Ministro Rafael Mayer. Brasília, 22 de maio de 1984.

30 Citação sem referência ao ano de publicação, da seguinte forma: BARBI, Celso Agrícola. Comentários ao Código de Processo Civil. Rio de Janeiro: Forense, [1977]. v. 1. p. 400.

31 Obra de 2006, citada da seguinte forma: GONÇALVES, Marcus Vinicius Rios. Novo curso de direito processual civil. 3. ed. São Paulo: Saraiva, 2006. v. 1. p. 58.

32 MATO GROSSO DO SUL. Tribunal de Justiça do Mato Grosso do Sul. Agravo Regimental em Agravo de Instrumento. AgReg em Ag 2010.014850-7/0001-00. 5a Turma Cível. Agravante: JLMR. Agravado: MBR. Relator: Desembargador Vladimir Abreu da Silva. Campo Grande, 12 de agosto de 2010. p. 10. de modo que não existiram as violações de lei arguidas pelo recorrente. $^{33}$

AHQ v. LRV (2013)

Narra-se que AHQ (autora) e LRV (réu), brasileiro nato, contraíram matrimônio em Pontevedra, Espanha. O casamento não foi regularmente registrado no Brasil. A autora se naturalizou brasileira após o matrimônio e ambos vieram a residir no Brasil. ${ }^{34}$

Posteriormente, a autora ajuizou ação de divórcio direto. Nascem, na mesma linha dos casos anteriores, questões da seguinte natureza: (i) é competente a justiça brasileiro para o divórcio, considerando não ter havido o registro do casamento no Brasil?; (ii) o divórcio, quanto ao regime de bens, será regido pelo direito brasileiro ou espanhol?

\section{Análise do Caso}

Quanto à competência, o juízo a quo reconheceu a incompetência internacional da justiça brasileira para conhecer do divórcio, tendo como motivo a ausência de registro da certidão de casamento no Brasil, de acordo com requisitos da Lei de Registros Públicos (art. 32 da Lei 6.015/73). Na apelação, a Relatora entendeu não ser uma hipótese de incompetência, uma vez que a exigência da LRP é apenas para efeito de publicidade do ato, tampouco de impossibilidade jurídica do pedido, uma vez que

não há nada no ordenamento jurídico em vigor que impeça o pedido de reconhecimento de divórcio direito, quando o casamento é realizado consoante as normas de outro país o pedido de divórcio direto litigiosos formulado contra brasileiro, sendo ambas as partes residentes no Brasil, é juridicamente possível, ainda que o casamento tenha sido realizado em território estrangeiro. ${ }^{35}$

3 MATO GROSSO DO SUL. Tribunal de Justiça do Mato Grosso do Sul. Agravo Regimental em Agravo de Instrumento. AgReg em Ag 2010.014850-7/0001-00. 5a Turma Cível. Agravante: JLMR. Agravado: MBR. Relator: Desembargador Vladimir Abreu da Silva. Campo Grande, 12 de agosto de 2010. p. 11.

34 BAHIA. Tribunal de Justiça do Estado da Bahia. Apelação. Ap 0045630-28.2004.8.05.0001. 1ª̂mara Cível. Apelante: AHQ. Apelado: LRV. Relator: Desembargador Maria da Purificação da Silva. Salvador, 04 de dezembro de 2013. p. $1-2$.

35 BAHIA. Tribunal de Justiça do Estado da Bahia. Apelação. Ap 0045630-28.2004.8.05.0001. 1 ${ }^{\text {a }}$ Câmara Cível. Apelante: AHQ. Apelado: LRV. Relator: Desembargador Maria da Purificação da Silva. Salvador, 04 de dezembro de 2013. p. 
O Acordão versa também sobre o direito aplicável ao divórcio. Faz a Relatora menção a dois momentos: (i) do matrimônio realizado, no qual é de se aplicar as normas então vigentes no ordenamento jurídico do país em que fora realizado", ou seja, da Espanha; e (ii) do divórcio, no qual devem ser aplicadas as normas do ordenamento brasileiro, nos termos do art. $7^{\circ}$ da LINDB, uma vez que o domicilio dos cônjuges era então o Brasil. ${ }^{36}$

Em suas palavras,

como os cônjuges são domiciliados neste país, sendo a autora brasileira naturalizada e o réu brasileiro nato, não há porque deixar de se aplicar ao caso as normas jurídicas brasileiras, pois divórcio é matéria de direito de família, inserindo-se, portanto, na dicção legal supratranscri$\mathrm{ta}^{37}$

Uma possível ressalva quanto à divisão temporal proposta pela Relatora incide sobre o regime de bens. Possuindo a LINDB (art. 7, \$4) (38 $^{38}$ previsão específica de que o regime de bens, no caso dos nubentes possuírem o mesmo domicílio, obedece à lei do país em que tiverem os nubentes domicílio, estariam os cônjuges vinculados ao regime de bens previsto na lei espanhola. Esse aspecto, entretanto, não é desenvolvido no caso, pois a argumentação da apelação se deu principalmente quanto à competência da justiça brasileira.

LFR v. GRS (2013)

Fechando o primeiro bloco de casos, narra-se que LFR (autora) se casou com o réu (GRS), em 2009, em Vancouver, no Canadá. Assevera a autora que foi enganada pelo réu, pedindo a anulação de seu casamento. Em primeiro grau, julgou-se extinto o pleito sem apreciação do mérito, em função de alegada incompetência internacional. ${ }^{39}$ Em apelação, além da questão da competência, a

\section{4.}

36 BAHIA. Tribunal de Justiça do Estado da Bahia. Apelação. Ap 0045630-28.2004.8.05.0001. 1 ${ }^{\text {a }}$ Câmara Cível. Apelante: AHQ. Apelado: LRV. Relator: Desembargador Maria da Purificação da Silva. Salvador, 04 de dezembro de 2013. p. 4. Grifou-se.

37 BAHIA. Tribunal de Justiça do Estado da Bahia. Apelação. Ap 0045630-28.2004.8.05.0001. 1 ${ }^{\text {a }}$ Câmara Cível. Apelante: AHQ. Apelado: LRV. Relator: Desa. Maria da Purificação da Silva. Salvador, 04 de dezembro de 2013. p. 4.

38 LINDB, art. 7: “ $\$ 40$ O regime de bens, legal ou convencional, obedece à lei do país em que tiverem os nubentes domicílio, e, se este for diverso, a do primeiro domicílio conjugal."

39 SÃO PAULO. Tribunal de Justiça de São Paulo. Apelação. Ap 0001422-55.2010.8.26.0100. 6a Câmara de Direito Privado. Apelante: LFR. Apelado: GRS. Relator: Desembargador Fortes Barbosa. São Paulo, 21 de março de 2013. p. 1-2. apelante argumentou que se deveria aplicar a lei brasileira quanto às hipóteses de anulação de casamento.

Os seguintes são exemplos das questões jurídicas advindas de casos dessa natureza: (i) qual lei rege os requisitos de forma e validade do casamento no estrangeiro? (ii) No caso do pedido de anulação no Brasil, é competente a autoridade judicial brasileira para decretá-lo? (iii) As hipóteses legais a serem consideradas para a anulação são as brasileiras ou as canadenses?

\section{Análise do Caso}

Sobre a validade e a eficácia de um casamento realizado no exterior, segundo a lei do Brasil, com apoio no ministério de Batiffol $^{40}$, Valladão ${ }^{41}$ e Dolinger ${ }^{42}$, indicou o Relator que casamentos no exterior, tradicionalmente,

se regem pela lei do lugar da celebração (locus regit actum), como o estabelecido desde meados do século XIX, como uma exceção à regra geral da nacionalidade ou do domicílio, regente dos conflitos de leis no direito de família, e é esta mesma lei que serve, também, para regular a forma da prova da celebração do casamento. ${ }^{43}$

Em seguida, corroborou a análise se referindo à longínqua doutrina de Miguel Maria de Serpa Lopes:

A nossa lei de introdução dispôs ser a lex loci celebrationis a que rege a forma extrínseca do casamento, quando celebrado em nosso País. A recíproca se impõe, e mesmo não há discrepância dos povos cultos [...] A prova do casamento é, em princípio submetida à lei relativa à forma, por conseguinte, à lei do lugar da celebração do ato. $^{44}$

Aplicando-se esses preceitos aos fatos, afirmou o Relator que o casamento em questão foi celebrado na Província da Columbia Britânica, no Canadá, sendo esta a legislação aplicável a ele para a prova de existência do casamento. Ademais, referiu-se à prova do casamento apresentada nos autos e na falta, até aquele momento, de

40 Obra de 1949, citada da seguinte forma: BATIFFOL, Henri. Traité Élémentaire de Droit International Privé. Paris: LGDJ, 1949. p. 454.

41 Obra de 1977, citada da seguinte forma: VALLADÃO, Haroldo. Direito internacional privado. 2. ed. Rio de Janeiro: Freitas Bastos, 1977. p. 62.

42 Obra de 1994, citada da seguinte forma: DOLINGER, Jacob. Direito internacional privado: parte geral. 3. ed. Rio de Janeiro: Renovar, 1994. p. 311.

43 SÃO PAULO. Tribunal de Justiça de São Paulo. Apelação. Ap 0001422-55.2010.8.26.0100. 6 6âmara de Direito Privado. Apelante: LFR. Apelado: GRS. Relator: Desembargador Fortes Barbosa. São Paulo, 21 de março de 2013. p. 3.

44 Obra de 1959, citada da seguinte forma: Miguel Maria de Serpa Lopes. Comentários à lei de introdução ao Código Civil. 2. ed. Rio de Janeiro Freitas Bastos, 1959. v. 2. p.105106. 
qualquer questionamento quanto à validade dos documentos, admitiu-os como atestatórios do ato.

No que toca à competência para apreciação do pedido, cingiu-se o Relator à previsão, nos termos do artigo 100, inciso I do CPC, de que dos cônjuges ostentava a nacionalidade brasileira e mantinha domicílio no Brasil. ${ }^{45}$ Por ocasião, já se opinou neste artigo que a questão relativa à competência internacional precede a do aspecto da competência relativa do artigo $100 .^{46}$

Por fim, com relação à aplicação do direito material - hipóteses de anulação do casamento - indicou a aplicação do artigo $7 \$ 3$ da $\operatorname{LINDB}^{47}$ ao caso, complementado, ainda, com referências a Dolinger ${ }^{48}$ e Basso ser uma daquelas "situações excepcionalíssimas em que um juiz brasileiro aplica o direito privado comum estrangeiro ao caso concreto." 49

Por questões relativas a pressuposto de precidibilidade da ação 3/4 envolvendo uma interpretação do art. 32 da Lei de Registros Públicos, ${ }^{50}$ a apelação, visando reformar a sentença a quo e anular o casamento, foi negada.

\section{Considerações Preliminares}

Ao se analisarem os aspectos factuais e de direito narrados, depreende-se a idiossincrasia de relações privadas conectadas a mais de uma jurisdição e, como se sugeriu, decorrentes da mobilidade de cidadãos globais. Em HG v. JG, essa mobilidade aponta para o Brasil e a Alemanha; em JLMR v. MBR, para o Brasil e o Paraguai; em AHQ v. LRB, para o Brasil e a Espanha; e, finalmente, em LFR v. GRS, para o Brasil e o Canadá.

HG v. JG ilustra problemas de competência para reconhecimento e dissolução de uma união estável mul-

45 SÃO PAULO. Tribunal de Justiça de São Paulo. Apelação. Ap 0001422-55.2010.8.26.0100. 6ª Câmara de Direito Privado. Apelante: LFR. Apelado: GRS. Relator: Desembargador Fortes Barbosa. São Paulo, 21 de março de 2013. p. 4.

46 Veja-se nota de rodapé 12

47 LINDB, art. 7: “\$30 Tendo os nubentes domicílio diverso, regerá os casos de invalidade do matrimônio a lei do primeiro domicílio conjugal."

48 Obra de 1997, citada da seguinte forma: DOLINGER, Jacob. Direito civil internacional: a família no direito internacional privado. Rio de Janeiro: Renovar, 1997. v. 1. p. 82.

49 SÃO PAULO. Tribunal de Justiça de São Paulo. Apelação. Ap 0001422-55.2010.8.26.0100. 6ª Câmara de Direito Privado. Apelante: LFR. Apelado: GRS. Relator: Desembargador Fortes Barbosa. São Paulo, 21 de março de 2013. p. 4.

50 SÃO PAULO. Tribunal de Justiça de São Paulo. Apelação. Ap 0001422-55.2010.8.26.0100. 6a Câmara de Direito Privado. Apelante: LFR. Apelado: GRS. Relator: Desembargador Fortes Barbosa. São Paulo, 21 de março de 2013. p. 6. ticonectada. A existência de bens na Alemanha faz surgir o problema da competência internacional da justiça brasileira para versar sobre sua divisão, embora se entenda que a Corte tenha se utilizado não apenas da questão da competência internacional, mas também do aspecto relativo ao tempo de aquisição do bem, como determinante para a decisão. Se a justiça brasileira fosse internacionalmente competente, o que não foi constatado no caso, a aplicação do direito material brasileiro sobre a partilha de bens em união estável, ou o que dissesse o direito alemão, entraria em debate. Em JLMR v. MBR, quanto à competência internacional para a divisão de bens, em matéria de divórcio, a decisão da Corte é oposta ao caso anterior. Constata-se, assim, potencial divergência na jurisprudência brasileira, sobre a extensão da competência doméstica para versar sobre partilha de bens no exterior, decorrente de divórcio ou dissolução de união estável.

Em AHQ v. LRV e no caso LFR v. GRS, adiciona-se aos tipos de problemas a discussão sobre a validade e eficácia de casamentos realizados no exterior (regidos pela lei do local de celebração), em cotejo com a Lei de Registros Públicos brasileira, havendo percepção distinta nas decisões sobre o efeito do não registro do ato no Brasil, para efeitos de competência internacional. Ademais, é de se chamar atenção que outros tipos de colisão de leis se delineiam, como o direito material substantivo aplicável às hipóteses de anulação de casamento.

Tomando o conjunto como um todo, embora didaticamente se tenham desagregado as questões em dois grandes pontos, percebe-se relação lógica entre eles, pois só há que se decidir sobre o direito aplicável se ultrapassada e conhecida a competência internacional para julgá-lo.

A próxima seção avança a mesma sistemática de narração e análise, sobre casos sucessórios multiconectados.

\subsubsection{Sucessão}

GGM v. UM e Outros (2004)

Trata-se de caso $^{51}$ de sucessão envolvendo cidadãos italianos e brasileiros e uma sequência complexa de fatos que aqui se apresentarão para melhor ilustração dos eventos.

51 DISTRITO FEDERAL. Tribunal de Justiça do Distrito Federal e Territórios. Apelação. Ap. 44.061/97. $3^{\text {a }}$ Turma Cível. Apelante: GGM. Apelado: UM e Outros. Relator: Desembargador J. J. COSTA CARVALHO. Brasília, 06 de maio de 2004. 
GM se casou com IV, na Itália, e, da relação, nasceu MPM, em 1944. Ainda em território italiano, GM se separou de fato de IV e constituiu uma companheira (ILM), com a qual teve a segunda filha, GGM. Em 1962, mudaram-se para o Brasil, GM, ILM e GGM, tendo nascido, em 1968, GCM. ${ }^{52}$

MPM permaneceu na Itália, casou-se com UM, e da união nasceram DM e FM. A figura seguinte ilustra as relações descritas.

Figura 1 - Relações de Parentesco em GGM v. UM e Outros

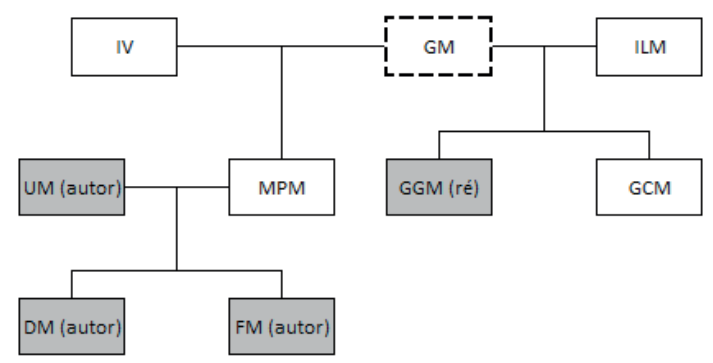

Fonte: Elaboração do autor

Em uma sequência trágica de eventos, ILM, GCM e GM faleceram, nessa ordem, no Brasil, entre 1985 e 1986. GGM requereu a abertura conjunta dos três inventários, como única herdeira e teve adjudicada para si todos os bens deixados pelo genitor GM, sem a inclusão da irmã MPM, posteriormente falecida em 1993.

UM, DM e FM foram autores em ação de petição de herança contra GGM pleiteando seus quinhões, por retificação de partilha, em virtude de o que juridicamente teria integrado o patrimônio de MPM. ${ }^{53}$

De interesse deste artigo, as questões advindas do caso podem ser assim enumeradas: (i) qual o alcance, sob a ótica internacional, da competência da justiça brasileira no caso?; (ii) Quais as implicações decorrentes da existência de sucessores de nacionalidade e domicílio na Itália, face a abertura da sucessão no Brasil?

52 DiSTRITO FEDERAL. Tribunal de Justiça do Distrito Federal e Territórios. Apelação. Ap. 44.061/97. 3a Turma Cível. Apelante: GGM. Apelado: UM e Outros. Relator: Desembargador J. J. COSTA CARVALHO. Brasília, 06 de maio de 2004. p. 3.

53 DISTRITO FEDERAL. Tribunal de Justiça do Distrito Federal e Territórios. Apelação. Ap. 44.061/97. 3a Turma Cível. Apelante: GGM. Apelado: UM e Outros. Relator: Desembargador J. J. COSTA CARVALHO. Brasília, 06 de maio de 2004. p. 3-4.

\section{Análise da Decisão}

Indicando o arrazoado pelo juízo a quo, relembra o Relator, em apelação, a reserva de jurisdição exclusiva no Brasil (art. 89) para questões sucessórias envolvendo bens no Brasil.

Em seguida, o Acordão discutiu, no mérito, o argumento levantado pela ré brasileira (GGM) de que como os herdeiros italianos não "aceitaram” a herança quanto aos bens localizados no Brasil, no processo de inventário aberto na Itália, por ocasião do falecimento de GM não teriam capacidade para suceder. $\mathrm{O}$ argumento se embasa na lei sucessória italiana. Alegadamente, DM e FM não teriam feito prova de ter, na Itália, aceitado a herança da mãe, conforme previsto no artigo 459 do Código Italiano, o qual deveria ser observada, de acordo com a regra de capacidade de suceder da regra de conflito brasileira ( $\$ 2$ do artigo 10 da LINDB) $)^{54}$. E, se não o fizeram, prescrito encontrar-se-ia tal direito, conforme artigo 480 do Código italiano. Além disso, a ré (GGM) invocou a lei brasileira que excluiria o direito do genro (UM) de postular a herança do sogro, pois, no Brasil, a herança seria deferida aos descendentes, excluindo as demais categorias.

O Relator resumiu o conflito espacial em análise. De um lado, o argumento da apelante de que os apelados não dispunham de capacidade sucessória, uma vez aplicada a lei italiana; de outro, o argumento dos apelados que a qualidade de herdeiro, e, assim, da vocação hereditária, haveria de ser processada à luz do caput do artigo 10 da LINDB, pela lei do domicílio do de cujus. ${ }^{55} \mathrm{O}$ Relator traz então jurisprudência do STJ, ${ }^{56}$ que, por sua vez, aludia à lição de Maria Helena Diniz, ${ }^{57}$ Oscar Tenório ${ }^{58}$ e Carlos Maximiliano, ${ }^{59}$ para confirmar a aplicação da lei brasilei-

54 LINDB, art. 10: "\$20 A lei do domicílio do herdeiro ou legatário regula a capacidade para suceder."

55 DISTRITO FEDERAL. Tribunal de Justiça do Distrito Federal e Territórios. Apelação. Ap. 44.061/97. $3^{\text {a }}$ Turma Cível. Apelante: GGM. Apelado: UM e Outros. Relator: Desembargador J. J. COSTA CARVALHO. Brasília, 06 de maio de 2004. p. 10.

56 Jurisprudência de (1997) citada como: BRASIL. Superior Tribunal de Justiça. Recurso Especial. REsp 61.434/SP. $4^{\mathrm{a}}$ Turma. , Relator: Min. César Asfor Rocha. Brasília, 17 de junho de 1997. p. 42.507.

57 Obra de 2000, citada da seguinte forma: Maria Helena Diniz. Lei de introdução ao Código Civil Brasileiro interpretada. 6. ed. São Paulo: Saraiva, 2000. p. 277-279.

58 Obra de 1955, citada da seguinte forma: Oscar Tenório. Lei de introdução ao Código Civil Brasileiro. 2. ed. Rio de Janeiro: Borsoi, 1955. p. 342.

59 Obra de 1943, citada da seguinte forma: MAXIMILIANO, Carlos. Direito das sucessões. 2. ed. São Paulo: F. Bastos, 1943. p. 584. 
ra, afastando-se a aplicação da lei italiana. Apoiou-se no comando do caput do artigo 10 da LINDB, último domicílio do de cujus, para apontar que o autor da herança havia falecido no Brasil e aqui deixados seus bens. ${ }^{60}$

Remeteu o Relator, mais uma vez, às lições de Maria Helena Diniz da distinção entre a lei que rege a situação do herdeiro (ou o seu direito à sucessão) da lei que rege a capacidade (ou aptidão) para suceder. No primeiro caso, a norma de sobredireito do DIPr brasileiro é a do caput do artigo $10^{\circ}$ (lex domicili do de cujus). Na segunda hipótese, a norma indicativa é a do $\$ 2$ do artigo $10^{\circ}$ da LINDB (lex domicili do herdeiro). ${ }^{61}$ A questão foi vista como pertinente ao primeiro grupo.

Entre outros pontos debatidos, negou-se provimento ao apelo.

Apesar da complexidade dos fatos do caso, entende-se que, claramente, tem-se sobre a mesa conflito entre leis brasileiras e italianas, em matéria de sucessão. Mais que isso. Expõe-se o denominado problema de "qualificação". No caso, girou em torno de se qualificar a questão dos herdeiros como relativa ao instituto da sucessão em si (o que atrairia a aplicação da lei brasileira, em função do caput do art. 10 da LINDB) ou como mera questão de capacidade sucessória (o que remeteria a lei material italiana, em função do $\$ 2$ do art. 10 da LINDB). Sem dúvida, como enfrentado pela corte, qualificar a questão como de uma ou outra natureza possui implicações diretas em conflito de leis e é tema de longínquo e discordante debate na doutrina de DIPr. ${ }^{62}$

\section{JCPS e THPS v. IIH (2012)}

Trata-se de peculiar caso de sucessão envolvendo alemães e brasileiros. Narra-se que OP e AP, alemães, proprietários de imóvel na Alemanha (bem em disputa), em 1943, formalizaram testamento conjuntivo. ${ }^{63}$

60 DISTRITO FEDERAL. Tribunal de Justiça do Distrito Federal e Territórios. Apelação. Ap. 44.061/97. 3ª Turma Cível. Apelante: GGM. Apelado: UM e Outros. Relator: Desembargador J. J. Costa Carvalho. Brasília, 06 de maio de 2004. p. 14

${ }^{61}$ DISTRITO FEDERAL. Tribunal de Justiça do Distrito Federal e Territórios. Apelação. Ap. 44.061/97. 3a Turma Cível. Apelante: GGM. Apelado: UM e Outros. Relator: Desembargador J. J. Costa Carvalho. Brasília, 06 de maio de 2004. p. 15-17.

62 Vejam-se: DOLINGER, Jacob. Direito internacional privado. 6. ed. Rio de Janeiro: Renovar, 2001. p. 361-383; JUENGER, Friedrich K. General Course on Private International Law. Hague, [1983]. p. 134-192-210. BOGGIANO, Antonio. Curso de derecho internacional privado. 2. ed. Buenos Aires: Abeledo-Perrot, 2000. p. 201-258.
Por ele, mutuamente se contemplavam: quem morresse primeiro deixaria para o outro a totalidade de seus bens. Além disso, em consonância com o direito alemão, estabeleceram que falecendo um dos dois filhos que tinham e os genitores, o herdeiro sobrevivente tudo herdaria, "isto é, não haveria sucessão por representação em favor dos descendentes do herdeiro morto." ${ }^{64}$

Com a Segunda Grande Guerra, o casal emigrou para o Brasil, o local do imóvel na Alemanha foi destruído e, uma vez instituído o regime comunista, passou à propriedade do Estado e dado como perdido pelos proprietários.

Quando da morte de OP e AP, o patrimônio no Brasil foi regularmente partilhado entre os herdeiros: a filha IIH e os sobrinhos JCPS e THPS, por representação (filhos do finado "H”, irmão pré-morto em relação a IIH). A figura abaixo busca facilitar a compreensão das relações descritas.

Figura 2 - Relações de Parentesco em JCPS e THPS v. IIH

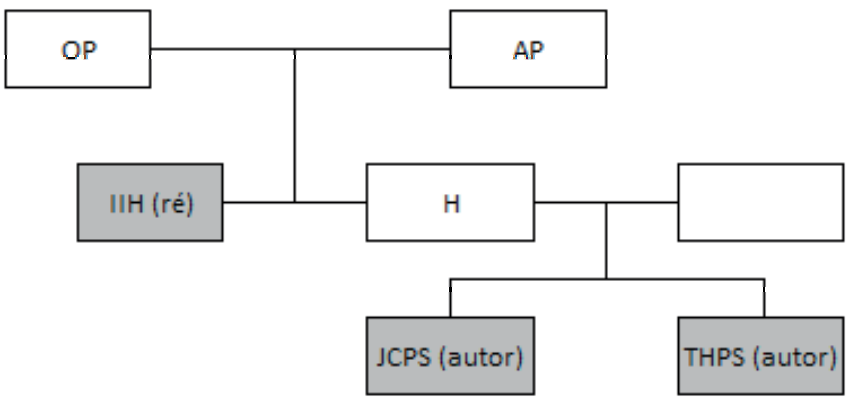

Fonte: elaboração do Autor

O imóvel na Alemanha, porém, com o fim do Regime Comunista e com a atuação de advogado naquele país, logrou ser reavido e atribuído exclusivamente a IIH, por força do testamento de 1943 que continha cláusula nesse sentido. IIH, em seguida, vendeu-o e ficou com o dinheiro do imóvel. ${ }^{65}$

ção. AP 9219247-49.2008.8.26.0000. 8ª Câmara de Direito Privado. Apelante: JCPS e THPS. Apelado: IIH. Relator: Desembargador Luiz Ambra. São Paulo, 31 de janeiro de 2012. p. 1-3.

64 SÃO PAULO. Tribunal de Justiça de São Paulo. Apelação. AP 9219247-49.2008.8.26.0000. 8ª Câmara de Direito Privado. Apelante: JCPS e THPS. Apelado: IIH. Relator: Desembargador Luiz Ambra. São Paulo, 31 de janeiro de 2012. p. 3.

65 SÃO PAULO. Tribunal de Justiça de São Paulo. Apelação. AP 9219247-49.2008.8.26.0000. 8a Câmara de Direito Privado. Apelante: JCPS e THPS. Apelado: IIH. Relator: Desembargador Luiz Ambra. São Paulo, 31 de janeiro de 2012. p. 4. 
Enumeram-se as seguintes questões do caso: (i) a justiça brasileira possui competência internacional em relação ao imóvel, objeto do testamento realizado na Alemanha em passado distante? (ii) Qual o direito aplicável à sucessão narrada?

\section{Análise da Decisão}

JCPS e THPS ajuizaram ação de sonegados ${ }^{66}$ tendo a sentença em primeiro grau decidido pela improcedência do pedido. Apelaram então da decisão surgindo, na discussão, o conflito de leis espacial: para $\mathrm{IIH}$, aplicar-se-ia, em relação ao imóvel, o previsto no testamento segundo o direito alemão. Para os sobrinhos (JCPS e THPS), cláusula dessa ordem não poderia prevalecer por contrariar o direito brasileiro.

O Relator entendeu que o testamento, em 1943, constitui-se em ato jurídico perfeito, segundo a lei daquele país. Não faria sentido se "viesse, cinquenta anos depois, a ser desconstituído por se chocar com a legislação de outro país, para onde os recíprocos testadores se mudaram." ${ }^{67}$ Relembrou, ainda, que o previsto no artigo $10, \$ 1$ da $\operatorname{LINDB}^{68}$ que trata de sucessão de bens de estrangeiros situados no país, leva à aplicação da lei mais benéfica aos herdeiros brasileiros. Mas uma vez interpretada a contrario sensu, os bens de estrangeiros situados no estrangeiro leva à aplicação do que indicar a lex rei sitae, no caso de imóveis.

Reforçou sua conclusão com a disposição do artigo 89, II do CPC, que limita a competência da justiça brasileira aos casos de inventário e partilha de bens situados no Brasil, quando o autor da herança é estrangei-

66 Código Civil, Art.1.992: "O herdeiro que sonegar bens da herança, não os descrevendo no inventário quando estejam em seu poder, ou, com o seu conhecimento, no de outrem, ou que os omitir na colação, a que os deva levar, ou que deixar de restituí-los, perderá o direito que sobre eles lhe cabia”.

67 SÃO PAULO. Tribunal de Justiça de São Paulo. Apelação. AP 9219247-49.2008.8.26.0000. 8ª Câmara de Direito Privado. Apelante: JCPS e THPS. Apelado: IIH. Relator: Desembargador Luiz Ambra. São Paulo, 31 de janeiro de 2012. p. 4.

68 LINDB, art. 10: “ $\$ 1^{\circ}$ A sucessão de bens de estrangeiros, situados no País, será regulada pela lei brasileira em benefício do cônjuge ou dos filhos brasileiros, ou de quem os represente, sempre que não lhes seja mais favorável a lei pessoal do de cujus." ro. ${ }^{69}$ Trouxe ainda as lições de Celso Agricola Barbi ${ }^{70}$ e Miguel Maria de Serpa Lopes ${ }^{71}$. Sobre o último, registrou que dava conta de ser o critério da legislação brasileira o critério denominado savigniano: imóveis e móveis de situação permanente se regem pela lex rei sitae; móveis que o proprietário tiver sempre consigo ou que forem do seu uso pessoal, ou os por ele conservados para a venda ou transporte para outro lugar, pela lei do domicílio do proprietário. Essa seria, inclusive, a inteligência da lei brasileira e a de outros países, como a Argentina.

Reforçou, por fim, ser este também o raciocínio trazido por Amílcar de Castro. ${ }^{72}$ que, inclusive, teria explicado a razão de adoção da fórmula lex rei sitae de uma maneira bastante direta:

QUAL A RAZÃO DE ADOÇÃO DO IUS REI SITAE? MOTIVOS DE ORDEM PRÁTICA, ECONÔMICOS, POLÍTICOS, DE CONVENIÊNCIA E UTILIDADE, JURÍDICOS PORTANTO, A MOSTRAR QUE O INTERESSE PARTICULAR NÃO TERIA NENHUM LUCRO E SOFRERIA A COLETIVIDADE INTEIRA SE A REGRA NÃO FOSSE ADOTADA; É O QUE DIZEM OS TRATADISTAS, ACRESCENTANDO QUE A MAIOR INCERTEZA REINARIA QUANTO À PROPRIEDADE SE PELA OBSERVÂNCIA DE UM SÓ DIREITO NÃO FOSSE REGULADA. NEM SE CONCEBE QUE OS DIREITOS DE PROPRIEDADE DE DOIS IMÓVEIS SITUADO NUM MESMO MUNICÍPIO BRASILEIRO FOSSEM APRECIADOS, UM PELO DIREITO BELGA, OUTRO PELO DIREITO INGLÊS, SOMENTE PORQUE SEUS ATUAIS PROPRIETÁRIOS FOSSEM UM BELGA E OUTRO INGLÊS. ALÉM DISSO, PUBLICIDADE SÓ PODE HAVER NO LUGAR DA SITUAÇÃO E MUITO SE DIFICULTARIAM AS TRANSAÇÕES SE NÃO FOSSE OBSERVADO O IUS REI SITAE. ${ }^{73}$

Por fim, apontou o dever de se resguardar o ato ju-

69 SÃO PAULO. Tribunal de Justiça de São Paulo. Apelação. AP 9219247-49.2008.8.26.0000. $8^{\text {a }}$ Câmara de Direito Privado. Apelante: JCPS e THPS. Apelado: IIH. Relator: Desembargador Luiz Ambra. São Paulo, 31 de janeiro de 2012. p. 5.

70 Obra de 1977, citada da seguinte forma: BARBI, Celso Agricola. Comentários ao Código de Processo Civil. Rio de Janeiro: Forense, 1977. v. 1. p. 401.

71 Obra de 1959, citada da seguinte forma: Miguel Maria de Serpa Lopes. Comentários à Lei de introdução ao Código Civil. 2. ed. Rio de Janeiro: Freitas Bastos, 1959. v. 1. p. 418.

72 Obra de 1977, citada da seguinte forma: Amílcar de Castro. Direito internacional privado. 3. ed. 1977. p. 407.

73 SÃO PAULO. Tribunal de Justiça de São Paulo. Apelação. AP 9219247-49.2008.8.26.0000. 8ª Câmara de Direito Privado. Apelante: JCPS e THPS. Apelado: IIH. Relator: Desembargador Luiz Ambra. São Paulo, 31 de janeiro de 2012. p. 7. Grifos retirados. 
rídico perfeito, no caso o testamento, segundo a lei alemã. Novamente, com o auxílio de Amílcar de Castro, transcreveu o preceito de que a capacidade para testar,

\begin{abstract}
pelo nosso sistema, é apreciada exclusivamente pelo direito em vigor no lugar de domicílio do testador, ao tempo de ser feito o testamento. É possível que o testador tenha um domicílio ao tempo de fazer o testamento, e outro na época do falecimento; e o que manda a doutrina dominante é que se avalie o ato pelo direito em vigor no domicílio que tinha ao tempo em que o praticou, pois a validade de qualquer ato juridicamente apreciável só pode ser aferida pelo direito a que devia obedecer [...]. ${ }^{74}$
\end{abstract}

Negou-se, ao final, o provimento da apelação.

Uma vez entendido o caso, nota-se mais uma vez a discussão sobre o conflito de leis de forma involucrada à competência internacional. E lá, como mostram os autos, IIH como experimentasse dúvidas acerca da condição de herdeiros dos sobrinhos, houve por bem externá-las ao advogado que houvera constituído naquele país [...]. Obtendo, em resposta [...], informação de que se trataria de herdeira única, segundo o direito alemão. ${ }^{75}$

Assim, ao aderir o Relator à tese de que os bens imóveis decorrentes de herança se regem pela lex rei sitae, independentemente de fazerem parte de uma universalidade, como previsto no art. 10 da LINDB, transferiu-se a discussão do conflito material para a jurisdição alemã.

\section{Considerações preliminares}

Os casos indicam particularidades, em matéria sucessória, de relações multiconectadas. Em GGM v. UM, conexões que apontam para o Brasil e a Itália; em JCPS v. IIH, para o Brasil e a Alemanha. A última contendo ainda a narrativa singular do surgimento de um imóvel dado como "perdido", em decorrência da Segunda Guerra Mundial e objeto de testamento na Alemanha com supostos herdeiros no Brasil.

Em GGM v. UM, uma vez que os bens relativos à causa sucessória estavam no Brasil, a discussão sobre competência foi facilmente ultrapassada. $\mathrm{O}$ ponto

74 SÃO PAULO. Tribunal de Justiça de São Paulo. Apelação. AP 9219247-49.2008.8.26.0000. 8ª Câmara de Direito Privado. Apelante: JCPS e THPS. Apelado: IIH. Relator: Desembargador Luiz Ambra. São Paulo, 31 de janeiro de 2012. p. 7-8.

75 SÃO PAULO. Tribunal de Justiça de São Paulo. Apelação. AP 9219247-49.2008.8.26.0000. 8ª̂amara de Direito Privado. Apelante: JCPS e THPS. Apelado: IIH. Relator: principal do conflito de leis girou em torno da qualificação da causa, como já explicado. Interessantemente, se visto como uma questão de mera capacidade sucessória, previa a lei italiana, se aplicada, solução destoante da brasileira. Excluir-se-iam os próprios herdeiros italianos que buscavam participação na herança deixada no Brasil.

Já em JCPS v. IIH, a discussão sobre competência foi fundamental para o desenrolar do caso. Implicou o não conhecimento, naquele caso, da competência internacional da justiça brasileira sobre o imóvel deixado em testamento na Alemanha. Além disso, houve um aspecto temporal expressivo a influir na decisão. O testamento era de 1943, válido segundo a lei alemã à época e protegido segundo o disposto pela Corte como ato jurídico perfeito pela lei brasileira.

Encerra-se, assim, a etapa de análise de casos, passando-se às conclusões para o fechamento do artigo.

\section{Conclusões}

Torna-se perceptível como a mobilidade de cidadãos globais problematiza o direito privado de família e sucessões. A utilização de estudos de casos para a introdução dessas problemáticas não é, decerto, uma técnica novel. Dolinger e Juenger, inspirações doutrinárias para este artigo, já o fizeram de forma primorosa. ${ }^{76}$

O objetivo do artigo era menos o de se posicionar contra ou a favor de determinada interpretação, mas enumerar tipos de problemas e distingui-los, esclarecendo parte de seus supostos "mistérios". Nessa feita, os casos foram analisados em dois grandes blocos. O primeiro deles compreendia, principalmente, o Direito de Família; o segundo bloco, o Direito Sucessório.

Sem pretensão de se exaurir a natureza e os tipos de problema jurídicos identificados, é de se citar:

1. HG v. JG, fatos: união estável de brasileira e alemão; domicílio cambiante entre Brasil e Alemanha; e dispersão de bens no Brasil e na Alemanha. Tipos de questões: justiça (doméstica ou internacional) competente para reconhecer e dissolver a união; justiça (doméstica ou internacional) competente para proceder à partilha dos bens; e direito aplicável à divisão dos bens;

2. JLMR v. MBR, fatos: casamento e divórcio entre brasileiros e bens dispersos no Para-

76 O primeiro no referido Curso de Haia (1983); o segundo, ao longo de sua extensa obra, no Brasil. 
guai. Tipos de questões: justiça (doméstica ou internacional) competente para proceder a partilha dos bens e direito aplicável à divisão dos bens dispersos, notando-se a interpretação distinta sobre os limites da competência internacional em relação ao caso anterior;

3. AHQ v. LRV, fatos: casamento no exterior entre brasileiro e espanhola naturalizada brasileira; falta de registro no Brasil; domicílio cambiante entre Brasil e Espanha; e divórcio. Tipos de questões: justiça (doméstica ou internacional) competente para conhecer do divórcio e direito aplicável ao divórcio, com distinção, pela Corte, de aspecto temporal;

4. LFR v. GRS, fatos: casamento no exterior entre brasileiro e canadense; domicílio cambiante entre os dois países; e anulação de casamento; Tipos de questões: justiça (doméstica ou internacional) competente para conhecer do divórcio e direito aplicável à anulação do casamento;

5. GGM v. UM, fatos: casamento e união de italianos na Itália; emigração para o Brasil; sucessão; bens no Brasil. Tipos de questões: justiça (doméstica ou internacional) competente para conhecer da matéria e qualificação da questão como sucessória per se ou relativa à capacidade de ser sucessor;

6. JCPS v. IIH, fatos: casamento de alemães na Alemanha; testamento na Alemanha; emigração para o Brasil; sucessão; surgimento de bem dado como perdido por ocasião da Segunda Guerra; dispersão de bens na Alemanha. Tipos de questões: justiça (doméstica ou internacional) competente para conhecer do caso; validade do testamento no estrangeiro e seu aspecto intertemporal.

Ressalvando-se a particularidade de um dos casos (expropriação de um bem pelo governo comunista pós Segunda Guerra Mundial), entende-se o quão atualizados são, bem como se chama a atenção para a tendência de incremento de situações similares, devido à mobilidade global.

Obviamente, na seara de Direito de Família e Sucessões, outros tipos de problemas multijurisdicionados, não identificados neste estudo, poderiam ter sido levantados. Poder-se-iam citar questões relativas à guarda de filhos e prestação de alimentos no exterior (sobre as quais incidem dispositivos de importantes Convenções), dispersão de bens em mais de duas jurisdições e objeções à aplicação ao direito estrangeiro, em função da violação da ordem pública. Certamente, objetos de tratamento em novos ensaios.

\section{Referências}

ARAUJO, Nadia de. Direito internacional privado. 4. ed. Rio de Janeiro: Renovar, 2008.

BAHIA. Tribunal de Justiça do Estado da Bahia. Apelação. Ap 0045630-28.2004.8.05.0001. 1ª Câmara Cível. Apelante: AHQ. Apelado: LRV. Relator: Desembargadora Maria da Purificação da Silva. Salvador, 04 de dezembro de 2013.

BOGGIANO, Antonio. Curso de derecho internacional privado. 2. ed. Buenos Aires: Abeledo-Perrot, 2000.

BRASIL. Decreto-Lei 4.657, de 4 de setembro de 1942. Lei de Introdução às normas do Direito Brasileiro. 1942. Brasília, 1942. Disponível em: <http://www.planalto.gov.br/ ccivil_03/decreto-lei/Del4657.htm>. Acesso em: 23 out. 2015.

BRASIL. Lei 13.105, de 16 de março de 2015. Novo Código de Processo Civil. Brasília, 2015. Disponível em: <http:// www.planalto.gov.br/ccivil_03/_Ato2015-2018/2015/Lei/ L13105.htm>. Acesso em: 23 out. 2015.

BRASIL. Lei 5.869, de 11 de janeiro de 1973. Institui o Código de Processo Civil. Brasília, 1973. Disponível em: $<$ http://www.planalto.gov.br/ccivil_03/leis/L5869.htm>. Acesso em: 23 out. 2015.

CASTRO, Amílcar de. Direito internacional privado. Rio de Janeiro: Forense, 1997.

DINIZ, Maria Helena. Lei de introdução ao Código Civil Brasileiro interpretada. São Paulo: Saraiva, 2000.

DISTRITO FEDERAL. Tribunal de Justiça do Distrito Federal e Territórios. Apelação. Ap. 20040110522404. $1^{\text {a }}$ Turma Cível. Apelante: HG. Apelado: JB. Relator: Desembargador Lécio Resende. São Paulo, 06 de agosto de 2009.

DISTRITO FEDERAL. Tribunal de Justiça do Distrito Federal e Territórios. Apelação. Ap. 44.061/97. 3a Turma Cível. Apelante: GGM. Apelado: UM e Outros. Relator: Desembargador J. J. Costa Carvalho. Brasília, 06 de maio de 2004.

DOLINGER, Jacob. Direito internacional privado. 6. ed. Rio de Janeiro: Renovar, 2001.

DOLINGER, Jacob. Evolução da ordem pública no direito internacional privado. Rio de Janeiro: Universitária, 1979.

DOLINGER, Jacob; TIBURCIO, Carmen. O DIP no Brasil no século XXI. Revista Mexicana de Derecho Internacional Privado, Cidade do México, número especial, p. 79-95, 2000. 
JUENGER, Friedrich K. General Course on Private International Law. Hague, [1983].

MATO GROSSO DO SUL. Tribunal de Justiça do Mato Grosso do Sul. Agravo Regimental em Agravo de Instrumento. AgReg em Ag 2010.014850-7/0001-00. 5a Turma Cível. Agravante: JLMR. Agravado: MBR. Relator: Desembargador Vladimir Abreu da Silva. Campo Grande, 12 de agosto de 2010.

MCLUHAN, M. A Galáxia de Gutenberg: a formação do homem tipográfico. São Paulo: Nacional, 1977.

RIBEIRO, Gustavo Ferreira; LUPI, André Lipp Pinto Basto. A aplicação do direito material estrangeiro em contratos pelos tribunais de justiça brasileiros: uma análise sobre dez anos de jurisprudência (2004-2013). Revista Nomos, Fortaleza, v. 34, n. 1, p. 81-107, jan/jun 2014.

SÃO PAULO. Tribunal de Justiça de São Paulo. Apelação. AP 9219247-49.2008.8.26.0000. 8a Câmara de Direito
Privado. Apelante: JCPS e THPS. Apelado: IIH. Relator: Desembargador Luiz Ambra. São Paulo, 31 de janeiro de 2012.

SÃO PAULO. Tribunal de Justiça do Estado de São Paulo. Apelação. Ap 0001422-55.2010.8.26.0100. 6ª Câmara de Direito Privado. Apelante: LFR. Apelado: GRS. Relator: Desembargador Fortes Barbosa. São Paulo, 21 de março de 2013.

WERNER, Goldshmidt. Derecho Internacional Privado: derecho de la tolerancia.7. ed. Buenos Aires: Depalma, 1990.

\section{Agradecimentos}

Este artigo contém resultados parciais de pesquisa empreendida pelo autor com o apoio do CNPQ, na modalidade Apoio Financeiro a Projeto, conduzido entre 2012-2014, denominado "Estrangeiros, Conflito de Leis no Espaço e os Rumos do Direito Internacional Privado nas Cortes Brasileiras", em conjunto com o Prof. André Lipp Pinto Basto Lupi. 